\title{
HOUSEHOLD FOOD SECURITY MONITORING AND EVALUATION USING A RESILIENCE INDICATOR: AN APPLICATION OF CATEGORICAL PRINCIPAL COMPONENT ANALYSIS AND SIMPLE SUM OF ASSETS IN FIVE AFRICAN COUNTRIES
}

\author{
M. Browne ${ }^{1}$, G.F. Ortmann ${ }^{2}$ and S.L. Hendriks ${ }^{3}$
}

${ }^{1}$ M.Sc. Agriculture student in Agricultural Economics, University of KwaZulu-Natal, Private Bag X01, Scottsville, Pietermaritzburg 3209. E-mail: browne.mich@gmail.com.

2 Professor of Agricultural Economics, University of KwaZulu-Natal, Private Bag X01, Scottsville, Pietermaritzburg 3209. E-mail: ortmann@ukzn.ac.za.

${ }^{3}$ Director: Institute for Food, Nutrition and Well-being and Assocaite Professor, Department of Agricultural Economics, Extension and Rural DevelopmentUniversity of Pretoria, Private Bag X20, Hatfield, Pretoria 0028. E-mail: sheryl.hendriks@up.ac.za.

\begin{abstract}
Recent global and African food crises have raised the importance of resilience as a determinant of the ability of households to cope with shocks and stresses that affect food security. This article sets out to develop a measure for resilience to provide a concise tool for measuring and monitoring food security in comparative ways across countries. It presents the results of the development of a resilience score tested using Demographic and Health Survey (DHS) household data for five African countries from two different time periods per country. Cluster analysis was used to classify households into socio-economic groups. The first index used Categorical Principal Component Analysis (CATPCA) and the second a simple sum of assets. Both indices were able to detect changes in household socio-economic status over the data periods in all five countries. However, the results for the two indices were not always consistent. The simple sum method results matched the published national Millennium Development Goal data more closely than the Categorical Principal Component Analysis method. The simple sum of assets has potential as an impact indictor for development programmes aimed at improving household food security and as a national to Millennium Development Goal indicator. It provides a simple tool for tracking resilience from data that is routinely collected through multiple in-country surveys and available from national statistics.
\end{abstract}


Keywords: household resilience, food security, assets, measuring and monitoring

JEL Classification: Q18

\section{INTRODUCTION}

Food security measurement has evaded researchers since the emergence of this term after the 1974 global food crisis. Numerous attempts to establish a measure for this complex and multifaceted concept have emerged in literature over the decades (for a review of food security measurements, see Hendriks, 2005). The most recent literature since the turn of the century has focused on measuring vulnerability (Alinovi et al., 2009). However, vulnerability is static and unable to predict the future capacity to absorb shocks that threaten household food security. Alinovi et al. (2009) explain that this is so for two reasons: conceptually, the multidimensionality of food security and the unpredictability of many shocks make vulnerability measures ineffective, and empirically, a lack of longitudinal data on various risks constrains the analysis of trends.

The 2008 global food crisis and more recently, the Horn of Africa crisis, have renewed focus on the need to build household resilience about food security. A number of continental and international frameworks for food security indicate the importance of building, protecting and promoting resilience. Frameworks such as the Global Strategic Framework currently under development through the Committee for World Food Security (CFS, 2011), the United Nations System Comprehensive Framework for Action (High Level Task Force on the Global Food Crisis, 2011), and the Comprehensive African Agricultural Development Programme's (CAADP) Framework for African Food Security (NEPAD, 2009), recognise the need for national governments to institute public programmes that focus on ensuring households are able to withstand and recover from shocks that threaten or reduce food insecurity. The Framework for African Food Security (FAFS) sets out Africa's plan of action to attain food security, improve agricultural productivity, develop dynamic regional and sub-regional agricultural markets, integrate farmers into a market economy and to achieve a more equitable distribution of wealth (Hendriks et al., 2009, citing NEPAD, 2003). The FAFS aims to ensure that agricultural growth simultaneously stimulates economic growth and reduces hunger and poverty to meet the first Millennium Development Goal (MDG). Evidence suggests that the 
inability to cope with risk and vulnerability plays a role in perpetuating poverty (Collier and Gunning, 1999; Dercon et al., 2005; Dercon, 2005; Dercon, 2006). An improvement in household resilience - the ability to cope with risk - could reduce vulnerability and food insecurity.

The FAFS recognizes the significance of resilience and risk management in reducing household poverty and has, as its first priority, the improvement of household risk management (or resilience). Table 1 sets out the key food security challenges identified in the FAFS and the solutions proposed to address these challenges and achieve the CAADP overall objectives. The CAADP Monitoring and Evaluation Framework sets out 32 indicators that countries are expected to report on at least annually to measure progress toward established CAADP and national goals for economic growth and reduction of poverty and hunger. However, due to the lack of concise and agreed on measures of food security, no indicators are currently included in the CAADP Monitoring and Evaluation Framework that directly measure food security.

Table 1: Summary of the FAFS challenges, solutions and proposed monitoring and evaluation indicators

\begin{tabular}{|l|l|l|}
\hline Food Security Challenges & Food Security Solutions & $\begin{array}{l}\text { Monitoring and evaluation } \\
\text { indicators }\end{array}$ \\
\hline $\begin{array}{l}\text { Inadequate food crisis management } \\
\text { at all levels }\end{array}$ & $\begin{array}{l}\text { Reduced risk and improved } \\
\text { resilience }\end{array}$ & No international measure available \\
\hline $\begin{array}{l}\text { Inadequate food supply and } \\
\text { marketing systems }\end{array}$ & Increased supply of affordable food & Proportion of income spent on food \\
\hline $\begin{array}{l}\text { Lack of income opportunities } \\
\text { Hunger, malnutrition and poor } \\
\text { dietary quality }\end{array}$ & Improved dietary diversity & Dietary Diversity \\
\cline { 2 - 3 } & Reduced malnutrition & Stunting* (height-to-age ratio) \\
\hline
\end{tabular}

Note: *Stunting can only be included if anthropometrics are available or if surveys record the last entry on a Road to Health card for small children. Otherwise, this variable can simply be omitted to give a 4-indicator score.

Sources: NEPAD (2009) and Hendriks (2011)

While internationally recognised measurements exist for the estimation of three of the four FAFS elements (income per capita, percentage income spent on food, and dietary diversity), measures for resilience do not exist (see Figure 1). The fifth measure (reduced malnutrition) 
included in the country scorecard in Figure 1, is proposed as an optional measure determined by rates of stunting. Determining malnutrition rates requires the use of anthropometric measurements, which are extensive, resource intensive and time consuming to collect. However, these statistics are often available in countries and provide the most direct measure of malnutrition and more accurate assessment of the situation.

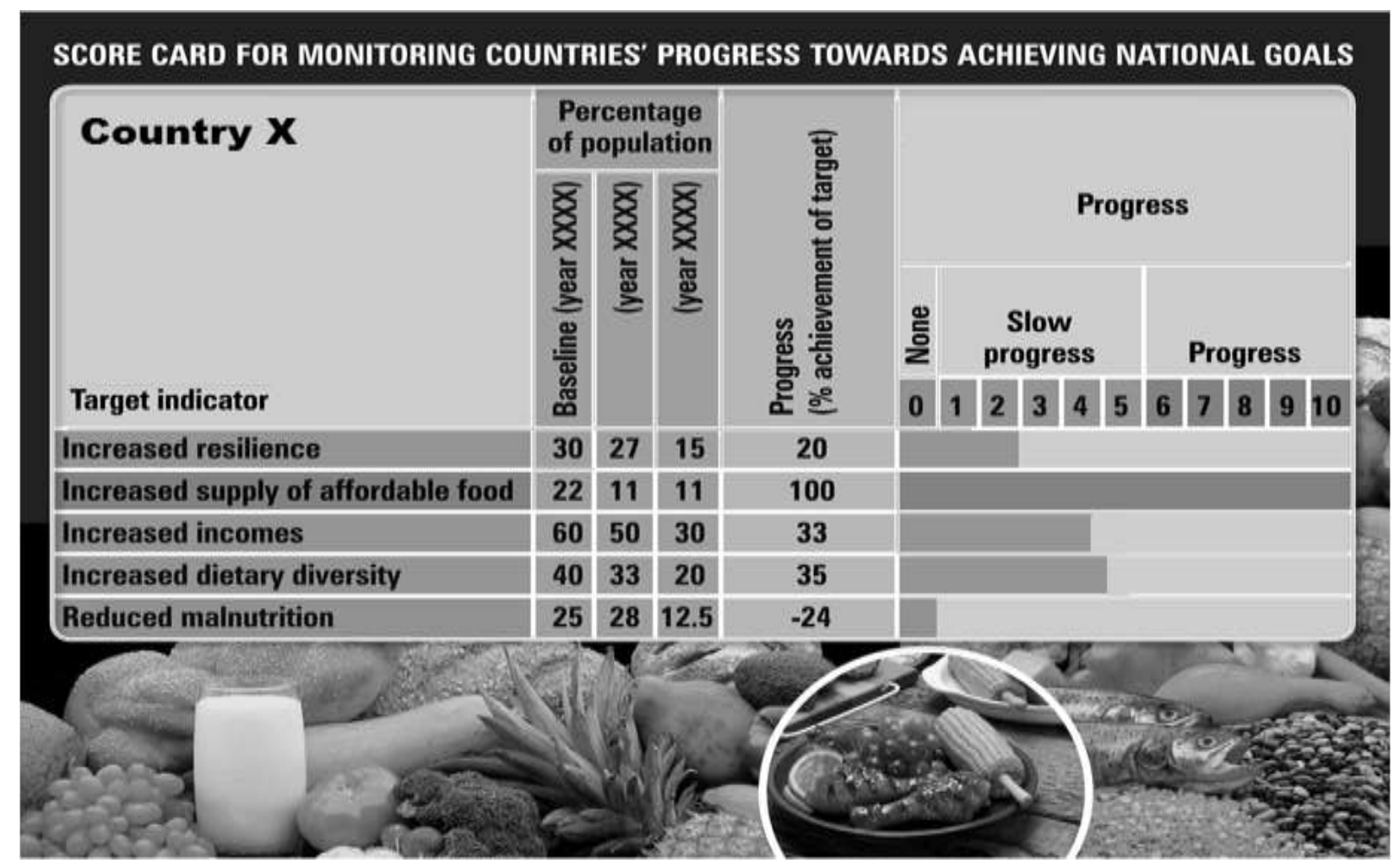

Figure 1: FAFS score card (Hendriks, 2011)

This article sets out to develop a measure for resilience to complete the scorecard and provide a concise tool for measuring and monitoring food security in comparative ways. It presents the results of the development of a resilience score tested using Demographic and Health Survey (DHS) household data for five African countries from two different time periods per country (Macro International Inc., 2010). Households were classified into socio-economic status groups by cluster analysis and the results for each country were compared over two sets of data to determine if the resilience index was able to detect changes in household socioeconomic status over time. Finally, the results were compared with published national poverty estimates.

This article is organized as follows. The first section presents a brief overview of the related literature. The next section describes the data and methodology. The results from the 
application of the index are presented and discussed in section four. Section five presents the conclusions and policy recommendations.

\section{LITERATURE REVIEW}

\subsection{Risk and resilience}

Risk is an important factor contributing to poverty and deprivation in the developing world (Kinsey et al., 1998; Dercon, 2006). Evidence suggests that the inability to cope with risk is an impediment to economic growth (Rosenzweig and Binswanger, 1993; Elbers et al., 2003; Dercon et al., 2005; Dercon, 2005; Dercon, 2006; Dercon and Christiaensen, 2008) and plays a role in perpetuating poverty (Collier and Gunning, 1999; Dercon et al., 2005; Dercon, 2005; Dercon, 2006). The decisions households make to mitigate risk have implications for poverty (Dercon, 2006). Some strategies may provide protection against shocks, but reduce incomes (Rosenzweig and Binswanger, 1993; Dercon et al., 2005; Dercon, 2006). For example, through diversifying agricultural crops, over specialising or opting not to adopt new technologies, households may avoid more profitable, yet risky activities, becoming permanently trapped in poverty (Dercon, 2006).. In this way, risk is itself a cause of poverty and an improvement in the ability to cope with risk could be a means of escaping poverty.

If the ability of food insecure households to cope with risk - resilience - can be improved, they would be more able to absorb shocks, cope with stresses, allocate resources to more profitable enterprises and improve their chances of escaping poverty. So too, improved resilience would reduce the burden on government resources and international aid. The FAFS acknowledges the importance of reducing risk and recognizes that an understanding of the resilience households possess is necessary in order to protect, provide and promote resilience at all levels (Hendriks, 2011). The framework seeks to promote the resilience of vulnerable populations in Africa (NEPAD, 2009).

\subsection{Household assets and resilience}

Sen (1981) explained that vulnerability (to famine) is a function of relative poverty and relative poverty is a function of a household's ownership of tangible assets and the rate at which these can be exchanged for food. Swift (2006) explains that a reduction in assets increases vulnerability to poverty and hunger. He concludes that a low asset status could be an indicator of vulnerability. Chambers (2006) gives support to Swift's suggestion and concludes that asset indicators need to be included in the design of appropriate measurement tools. 
Similarly, Maxwell and Smith (1992) propose that asset holdings could be used as an indicator of food insecurity. Moser (1998) suggests that vulnerability to hunger is a result of threats and a lack of resilience. Assets and entitlements provide liquidity during times of stress (Moser and Holland, 1997; Moser, 1998). Therefore, food insecurity is linked to asset ownership: the lower the asset ownership, the higher the likelihood of food insecurity (Moser, 1998). In their discussion of the measurement of vulnerability, Lovendal and Knowles (2005) suggest that asset values could be used as a proxy of the ability of a household to cope with shocks. They explain that assets are an important part of risk management as they can be used to smooth consumption, and access to assets influences the ability to prevent, mitigate and cope with shocks.

From the literature it is clear that the presence of risk may perpetuate poverty, whereas improved resilience may be a means of overcoming poverty. Assets play a role in a household's ability to cope with risk. Therefore, if asset ownership could be "measured", the outcome would give an indication of a household's resilience. Asset-based indices have been used in several studies (Filmer and Pritchett, 1994; 1999; 2001; Rutstein and Johnson, 2004; McKenzie, 2005; Gwatkin et al., 2007), giving an indication of the wealth of assets owned by a particular household. This, in turn, could be used as a relative indication of household resilience. Therefore, based on the premise that the level of asset ownership is an indication of a household's ability to cope with risk, an asset-based index could be used to estimate a socioeconomic status score as an indicator of the relative resilience of the particular household.

\section{RESEARCH METHODOLOGY}

In this study, an asset-based index was used to estimate household resilience scores for 10 DHS datasets taken from five countries for two different time periods per country. The households were grouped into five clusters of increasing resilience using cluster analysis. The proportion of households falling into the clusters was compared for each country across the two time periods to determine whether changes in resilience could be detected over time.

\subsection{Data description}

The data used in the study were taken from the household component of the DHSs for five African countries. The DHSs are large, nationally representative household surveys with a focus on obtaining nationally representative and cross-nationally comparable household level data to plan, monitor and improve population, health and nutrition programmes. The surveys are an extensive, reliable source of data for health and demographic analysis in developing 
countries (Kolenikov and Angeles, 2009; Measure DHS, undated). The survey questionnaires are based on a generic survey, with some contextualisation for specific country context (Measure DHS, undated), as such, the assets included in the survey differ across countries.

The Human Development Report (UNDP, 2009) lists countries in order of the proportion of the population living below US\$1.25 per day. The countries were selected by grouping the African countries appearing in the report into three categories - rich, middle and poor - based on their United Nations Development Programme (2009) poverty ranking. Countries from each category with a DHS version five - the most recent round of DHS surveys - were selected for analysis. The five countries chosen were Tanzania $(2004,2007)$ from the "poor" category; Mali $(2001,2006)$ and Uganda $(2000,2006)$ from the "middle" category; and Egypt $(2005,2008)$ and Kenya $(2003,2008)$ from the "rich" category. While the datasets were not from the same years, the study aimed at investigating if the resilience indicator could detect changes over time. The results for each country are, therefore, not comparable across countries.

\subsection{Resilience index construction}

The variables included in the two indices were taken from variables related to asset ownership and characteristics of the household dwelling available in the DHS datasets. These included variables such as "owns a car", "owns a phone" and "owns a television" for the asset ownership variables and "type of toilet facility", "source of drinking water" and "has electricity" for the household characteristics variables. The indices were not identical for each country due to variations in the data.

PCA is a widely used means of generating the weights for the variables included in an asset index; therefore, the chosen variables must also meet the assumptions of PCA. PCA is based on the assumptions that variables have at least an interval level of measurement and are linearly related to one another (Linting, 2007). In the case of categorical data, these assumptions may be violated and the application of standard PCA to such data may lead to serious problems (Linting, 2007). Linting (2007), among others (Meulman et al., 2004a; Meulman et al., 2004b; Linting et al., 2007; Costantini et al., 2010; Mair and de Leeuw, 2010; Manisera et al., 2010), suggests the use of nonlinear PCA as a means of dealing with categorical data.

Sampling adequacy, suitability for data reduction and no significant outliers are additional assumptions underlying the application of PCA. In this study, five country datasets were used; the smallest dataset used had a sample size (N) of 8497 households and the 
average sample size was 11678 households. As a first step in the selection of the indicator variables for inclusion in the index, descriptive analyses were carried out for all possible variables from each of the chosen countries' DHS datasets. While descriptive analyses assist the selection of variables, they are also a useful tool for detecting issues such as missing values and coding errors (Vyas and Kumaranayake, 2006). However, the mean and standard deviation estimates are only useful for the durable asset variables with only two categories, such as "owns a radio" or does not. The mean and standard deviation for the durable asset variables, as well as the number of missing values for all variables, were then examined. The correlations between variables were also considered, as an indication of the variables' suitability for PCA. The variables for inclusion in the index were chosen based on these statistics. Variables with high levels of missing values were excluded. No numeric variables were included in the indices; as such there were no significant outliers.

A number of the variables included in the asset indices were categorical in nature, therefore, the first resilience index was estimated using a Categorical Principal Component Analysis (CATPCA), available in SPSS Categories 10 onwards (Meulman et al., 2004a; Meulman et al., 2004b). Nonlinear PCA has been suggested as a solution to the possible inappropriateness of applying standard (linear) PCA to categorical data when these variables may not fulfil the assumptions of linear relationships between variables and a measurement scale at least on the interval level (Meulman et al., 2004a; Meulman et al., 2004b; Linting, 2007; Linting et al., 2007; Costantini et al., 2010; Mair and de Leeuw, 2010; Manisera et al., 2010). A detailed discussion of the mathematics of nonlinear PCA is given by Gifi (1990), Meulman et al. (2004b) and Linting (2007).

The scores were generated by applying CATPCA to the variables selected from each country dataset to determine the indicator weights for the variables. Once the indicator weights had been estimated and the index of resilience constructed, the index was applied to the individual households and a score for each household was calculated using Equation (1):

$$
A_{j}=f_{1} \times\left(a_{j 1}-a_{1}\right) /\left(s_{1}\right)+\ldots+f_{N} \times\left(a_{j N}-a_{N}\right) /\left(s_{N}\right)
$$

where $A_{j}$ was the resilience score for household $j, f_{1}$ was the component loading generated by CATPCA for the first variable, $a_{j 1}$ was the $j^{\text {th }}$ household's value for the first variable, and $a_{1}$ and $s_{1}$ were the mean and standard deviation, respectively, of the first variable over all the households. As an alternative to using a statistical means of generating weights for an index of resilience, a simple count of household possessions could be used to generate a score of 
resilience, as done for socio-economic status by Hatloy et al. (2000), Montgomery et al. (1999) and Garenne and Hohmann-Garenne (2003). A list of household possessions was selected from those available in the DHS datasets for each of the chosen countries, and recoded as dummy variables with a value of one assigned to the category linked to a higher level of socio-economic status and zero otherwise. Consequently, the final index score was simply a sum of all the dummy variables.

\subsection{Household classification}

Once the individual household scores had been estimated (using both methods) for both time periods for each country dataset, k-means cluster analysis was used to classify the households into groups of similar levels of resilience. Cluster analysis is a technique used to identify homogeneous groups of cases in multivariate datasets (Norusis, 2008:359). The cases are grouped based on the values of the selected variables so that "similar" cases fall into the same group or cluster (Manly, 1994:128). k-means clustering was chosen for the analysis of the country household data in this study as dataset sizes exceed 1000 cases: Garson (2010) suggests k-means cluster analysis is appropriate when $N$ exceeds 1000 . The results for each country over the two time periods were then compared.

\section{RESULTS AND DISCUSSION}

\subsection{Resilience comparison over time - CATPCA}

The resilience index applied in this section was constructed by means of the CATPCA method. The households were classified into five groups representing different levels of resilience using k-means cluster analysis of the estimated resilience scores. The cluster sizes as a proportion of the total population - are presented by country and year in Table 2. Each cluster represents a different level of resilience - least to most resilient. The proportion of the sample allocated to each cluster represents the proportion of sample households allocated to the five categories or levels of resilience. Comparisons were drawn between the resilience scores of the two different years. There were slight differences in the variables included in the construction of the indices between the years due to the variation between countries. Therefore, direct comparisons of the scores were not entirely reliable and should not be given too much attention. In the discussion below the terms "poor", "rich" and "forms" thereof are used loosely to describe differences in resilience: the estimated resilience scores are relative to one another within each dataset and give no indication of absolute levels of poverty or wealth. 
Table 2: Cluster sizes (proportion of total sample) by country and year, based on the estimated household resilience scores using the CATPCA index and k-means cluster analysis with five clusters

\begin{tabular}{|l|l|l|l|l|l|l|l|}
\hline \multirow{2}{*}{ Country } & Year & \multicolumn{4}{l}{$\begin{array}{l}\text { Proportion of total sample allocated to each cluster/level of } \\
\text { resilience (\%) }\end{array}$} & Total (\%) \\
\cline { 3 - 8 } & Least & Less & Nominal & More & Most & \\
\hline \multirow{2}{*}{ Egypt } & 2005 & 8.3 & 24.0 & 34.7 & 22.5 & 10.5 & 100 \\
\cline { 2 - 8 } & 2008 & 10.4 & 31.6 & 30.9 & 19.4 & 7.7 & 100 \\
\hline \multirow{2}{*}{ Kenya } & 2003 & 43.3 & 30.9 & 14.1 & 7.6 & 4.1 & 100 \\
\cline { 2 - 8 } & 2008 & 30.3 & 32.6 & 19.9 & 12.2 & 5.0 & 100 \\
\hline \multirow{2}{*}{ Mali } & 2001 & 57.4 & 28.7 & 7.8 & 3.9 & 2.2 & 100 \\
\cline { 2 - 8 } & 2006 & 65.8 & 19.3 & 8.9 & 4.0 & 1.9 & 100 \\
\hline \multirow{2}{*}{ Uganda } & 2000 & 43.2 & 30.5 & 16.0 & 7.5 & 2.8 & 100 \\
\cline { 2 - 8 } & 2006 & 45.3 & 31.9 & 12.7 & 6.9 & 3.2 & 100 \\
\hline \multirow{2}{*}{ Tanzania } & 2004 & 61.8 & 21.2 & 10.0 & 4.6 & 2.4 & 100 \\
\cline { 2 - 8 } & 2007 & 58.0 & 24.9 & 9.0 & 6.4 & 100 \\
\hline
\end{tabular}

Note: Relative resilience increases from the least resilient cluster to the most resilient cluster.

Source: Survey data (various years).

For three of the five countries analysed, the results showed an increase in the proportion of households allocated to the cluster of least resilience (cluster 1) from the earlier time period to the more recent period. For Kenya and Tanzania, there was a decrease in the proportion of households allocated to the least resilient level. The results also indicated that the proportion of households allocated to the most resilient group (cluster 5) decreased from the earlier time period to the more recent period for three of the five countries. For Kenya and Uganda, the proportion of households assigned to the most resilient cluster increased slightly.

The cluster containing the highest proportion of households for the 2005 Egypt analysis was the cluster of nominal resilience, whereas for the 2008 analysis the largest cluster was the less resilient cluster. Along with the increase in the proportion of households allocated to the cluster of least resilience from 2005 to 2008, this result suggests that a relatively larger proportion of households were relatively less resilient than their counterparts in 2008 compared with 2005. 
This conclusion was reflected in a decrease in the highest resilience score between 2005 (18.77) and 2008 (18.1) and the lower mean resilience score for the most resilient cluster of the 2008 period. However, the lowest resilience score did not decrease from 2005 (-19.96) to 2008 (-17.30) and the mean score of the least resilient cluster was actually higher for the 2008 year. It could be concluded that for Egypt, a higher proportion of the population was relatively less resilient in 2008 than in 2005, yet the extremely vulnerable were better off in terms of resilience in the later period. The differences in mean scores between the clusters were more similar for the 2008 analyses compared with the 2005 results, suggesting that resilience was more broadly evident in 2008 that in 2005. The conclusions drawn assume the samples were representative of the population.

For Kenya, there was a decrease in the proportion of households allocated to the cluster of least resilience and an increase in the number of households allocated to all the other clusters between 2003 and 2008. For the 2003 analysis, the largest proportion of households was allocated to the least resilient cluster whereas for 2008 the largest cluster was the less resilient one. The maximum resilience score was higher for 2008 (23.14) than 2003 (20.42) and so was the mean resilience score for the most resilient cluster. However, the minimum resilience score was lower for 2008 than 20054Similarly the mean resilience score for the least resilient cluster was lower for 2008 than 2003.

For Kenya, it was concluded that a lower proportion of the population was extremely vulnerable in 2008 than in 2003, yet the most vulnerable were worse off in 2008 as shown by the lower minimum score and lower mean score for the least resilient cluster for the 2008 year. The differences in the mean scores between clusters were more similar for the 2003 analysis, suggesting lower inequality across households in 2003 than in 2008. The difference between the minimum and maximum resilience scores for 2008 (32.92) implies a more generalised or widespread resilience in 2008 than in 2003 (27.06).

The results for Mali suggest there was an increase in extreme poverty between 2001 and 2006 as shown by the increase in the proportion of households allocated to the least resilient cluster. The extremely poor were worse off as indicated by a lower minimum resilience score, as well as a lower mean score for the least resilient cluster for 2006 compared with 2001. The proportion of households allocated to the most resilient cluster decreased from 2001 ( 2.2 per cent) to 2006 (1.9 per cent), and the relatively more resilient households appear to have more assets in 2006 than 2001 as both the mean score for the most resilient cluster and the maximum score were higher in 2006 than in 2001. 
The Ugandan results indicate an increase in extreme poverty between 2000 and 2006, although the change is slight -43.2 per cent of the population fell into the least resilient cluster for the 2000 period and 45.3 per cent for the 2006 period. There was also a slight decrease in the mean resilience score for the least resilient cluster between $2000(-4.28)$ and 2006 (-5.21). Additionally, there was a small increase in the proportion of households assigned to the most resilient cluster between 2000 (2.8) and 2006 (3.2) and an increase in the mean score for this cluster from 2000 (18.65) to 2006 (23.60). The differences in mean scores between the clusters were more similar for the 2000 analysis, suggesting that household resilience in Uganda was more evenly distributed in 2000 than in 2006.

For Tanzania, from 2004 to 2007, there was a decrease in the proportion of households allocated to the lowest level of resilience as well as a decrease in the proportion of households falling into the most resilient category. However, these changes were relatively small. The mean resilience score for both the relatively poor and more resilient clusters decreased slightly from 2004 to 2007 as did the minimum score for the total sample. From these observations it was concluded that the overall level of resilience decreased from 2004 to 2007 for households in Tanzania. The differences in the mean resilience score between the clusters were comparable for the two time periods, suggesting that the distribution of resilience in 2007 was similar to that in 2004.

The discussion above demonstrates how the resilience index combined with k-means cluster analysis could be used to monitor changes in household resilience over time. However, this measure only gives an indication of adjustments in the proportion of households falling into the relative categories of resilience over time and does not give any indication of the actual level of resilience represented by the clusters. The estimated scores are relative and their values are not directly comparable between countries: the actual levels of resilience represented by the clusters for one country are not necessarily the same for another and the scores do not indicate actual levels of resilience or food insecurity.

\subsection{Resilience comparison over time - simple sum of assets}

The CATPCA method of asset weight estimation is time consuming as the variables have to be recoded twice - once before CATPCA is applied and once after - to achieve the final ordering of the categories and weights for each variable. The additional recoding processes may introduce a number of computational errors into the analysis. The simple sum method is quicker to apply and less susceptible to computational errors as only the dichotomous 
variables are used in their binary form. In order to investigate the possibility of using the simple sum method instead of the CATPCA method, the comparison of household socioeconomic status over time was repeated using the simple sum method of weight estimation. The results are presented in Table 3 as the proportion of households allocated to each cluster by country and year.

Table 3: Cluster sizes (proportion of total sample) by country and year, based on the estimated household resilience scores using the simple sum index and k-means cluster analysis with five clusters

\begin{tabular}{|c|c|c|c|c|c|c|c|}
\hline \multirow[t]{2}{*}{ Country } & \multirow[t]{2}{*}{ Year } & \multicolumn{5}{|c|}{$\begin{array}{l}\text { Proportion of total sample allocated to each cluster/level of } \\
\text { resilience (\%) }\end{array}$} & \multirow[t]{2}{*}{ Total (\%) } \\
\hline & & Least & Less & Nominal & More & Most & \\
\hline \multirow[t]{2}{*}{ Egypt } & 2005 & 3.9 & 15.6 & 56.6 & 18.8 & 5.1 & 100 \\
\hline & 2008 & 3.7 & 15.8 & 58.9 & 18.4 & 3.3 & 100 \\
\hline \multirow[t]{2}{*}{ Kenya } & 2003 & 54.9 & 31.8 & 5.9 & 6.7 & 0.7 & 100 \\
\hline & 2008 & 32.3 & 33.2 & 28.4 & 5.3 & 0.8 & 100 \\
\hline \multirow[t]{2}{*}{ Mali } & 2001 & 20.5 & 59.4 & 15.1 & 3.7 & 1.2 & 100 \\
\hline & 2006 & 42.8 & 45.2 & 8.7 & 2.3 & 1.0 & 100 \\
\hline \multirow[t]{2}{*}{ Uganda } & 2000 & 47.5 & 34.2 & 13.0 & 4.0 & 1.3 & 100 \\
\hline & 2006 & 22.0 & 53.1 & 16.3 & 6.1 & 2.5 & 100 \\
\hline \multirow[t]{2}{*}{ Tanzania } & 2004 & 29.2 & 59.9 & 6.9 & 3.4 & 0.6 & 100 \\
\hline & 2007 & 23.3 & 66.6 & 7.0 & 2.8 & 0.3 & 100 \\
\hline
\end{tabular}

Note: Relative resilience increases from the least resilient cluster to the most resilient cluster.

Source: Survey data (various years).

The direction and size (in percentage points) of the change in the proportion of households allocated to the clusters between the first and second data sets for the CATPCA and simple sum (SS) methods are presented in Table 4. 
Table 4: The change in cluster sizes (percentage points) from the first year to the second year of analysis for the five countries and both methods of index construction

\begin{tabular}{|l|l|l|l|l|l|l|l|l|l|l|}
\hline Country & \multicolumn{2}{l}{ Change } \\
\cline { 2 - 13 } & \multicolumn{2}{l}{ Least resilient } & \multicolumn{2}{l|}{ Less resilient } & \multicolumn{2}{l|}{$\begin{array}{l}\text { Nominally } \\
\text { resilient }\end{array}$} \\
\cline { 2 - 13 } & CATPCA & SS & CATPCA & SS & CATPCA & SS & CATPCA & SS & CATPCA & SS \\
\hline Egypt & 2.1 & -0.3 & 7.6 & 0.2 & -3.8 & 2.3 & -3.1 & -0.4 & -2.8 & -1.9 \\
\hline Kenya & -13.0 & -22.6 & 1.7 & 1.4 & 5.8 & 22.5 & 4.6 & -1.4 & 0.9 & 0.1 \\
\hline Mali & 8.4 & 22.3 & -9.4 & -14.2 & 1.1 & -6.4 & 0.1 & -1.4 & -0.3 & -0.2 \\
\hline Uganda & 2.1 & -25.5 & 1.4 & 18.9 & -3.3 & 3.3 & -0.6 & 2.1 & 0.4 & 1.2 \\
\hline Tanzania & -3.8 & -5.9 & 3.7 & 6.7 & -1.0 & 0.1 & 1.8 & -0.6 & -0.7 & -0.3 \\
\hline
\end{tabular}

Note: Relative resilience increases from the least resilient cluster to the most resilient cluster.

CATPCA refers to Categorical Principal Component Analysis.

SS refers to Simple sum of assets.

Source: Survey data (various years).

From these results it is clear that neither the size nor the direction of the change was the same for both methods across all the countries. For example, the simple sum results for Egypt showed that the proportion of households in the least resilient cluster decreased by 0.3 percentage points from 2005 to 2008, whereas the results from the CATPCA-based classification showed an increase of 2.1 percentage points. Both methods showed a decrease in the proportion of households allocated to the most resilient cluster from 2005 to 2008, although the size of the change was larger by the CATPCA method. Similar discrepancies between the methods are apparent throughout the results. The changes in the proportion of households allocated to the different levels of resilience differ depending on the method of index construction. In this case, using the CATPCA method produced different, and often opposite, trends in the movement of households between levels of resilience over time to the simple sum method. While the simple sum method offers a quicker, easier means of constructing an index of resilience, it uses less information and this omission of information clearly affects the classification results. The method of index construction does affect the household classification outcomes and the trends in the movement of households between clusters over time. In other words, not only does the method of index construction affect the actual cluster sizes, it also affects the direction of changes in the cluster sizes over time. 


\subsection{Comparison of results with reported poverty estimates and methods}

If asset ownership is taken as a proxy for income, comparison of the resilience score changes over time can be compared with trends in poverty data for the same countries over the same time periods. The Millennium Development Goals Report for Egypt for 2010 (Ministry of Economic Development - Egypt, 2010) reflected a three-percentage point fall in the incidence of poverty in Egypt between 2005 and 2008. The incidence of poverty is calculated as the proportion of the population living below US\$1.25 per day (Ministry of Economic Development - Egypt, 2010). This outcome is in line with the conclusions drawn from the simple sum results, but in contrast to results of the CATPCA method.

The Egypt Human Development Report (HDR) for 2008 (UNDP, 2008) puts the poor, as a proportion of the total population, at 20.7 per cent for 2004 and 19.6 per cent for 2006 based on the national poverty line for Egypt. The 2010 HDR indicates that 21.6 per cent of the population was poor in the 2008/09 period. These figures suggest an increase in the proportion of the poor in Egypt between 2005 and 2008, which is in line with the conclusions drawn from the CATPCA results, but in contrast to results of the simple sum method.

A study conducted by the World Bank in Kenya over the 1997-2005/06 time period (World Bank, 2008) showed a decrease in poverty by 5.5 per cent, but no reduction in the severity of poverty, and concluded that the poorest of the poor lost out in absolute terms. There was an increase in the income levels of the rich and inequality worsened. The study used the cost of buying the amount of energy sufficient to meet the recommended daily nutritional requirements and minimal non-food needs as a poverty threshold. The conclusions drawn from the World Bank analysis (World Bank, 2008) lend support to the results obtained in this study.

However, outcomes of an investigation of poverty dynamics in Kenya over the 1997 to 2007 period by Suri et al. (2009) are somewhat different. Suri et al. (2009) also found a decrease in the proportion of the poor - poverty levels fell from 50.0 per cent to 37.6 per cent from 1997 to 2007. An individual was defined as poor if he/she fell below a pre-determined level of economic welfare. However, their estimates showed an increase in the incomes of the poorest by 30.0 per cent. Suri et al. (2009) concluded that the poorest of the poor were better off in 2007 than in 1997. The incomes of the richest decreased by 20.0 per cent and overall income equality fell. Suri et al's. (2009) results differ from the conclusions drawn from the changes in resilience estimated for Kenya in this study. However, the time periods considered 
in each of the three studies discussed differ slightly, which may partly account for the difference in outcomes.

For both the CATPCA and simple sum methods, the results for Mali indicate an increase in the proportion of extremely poor households during the 2001 to 2006 period. Conversely, the Poverty Reduction Strategy Paper for Mali 2006 (IMF, 2008) reports a decline in poverty between 2001 and 2005 that is attributed mainly to a fall in urban poverty. The Poverty Reduction Strategy Paper for Mali 2006 indicates that there was also a reduction in the degree and severity of poverty. This outcome is consistent with the conclusion drawn from the simple sum method results of a lower level of resilience. However, the CATPCA method results implied that the level of resilience worsened in Mali between 2001 and 2006.

The 2010 Millennium Development Goals Report for Uganda (Ministry of Finance, Planning and Economic Development - Uganda, 2010) reported poverty headcounts of 34.0 per cent (the per cent of the population living below one US dollar per day) for the 1999/2000 period and 31.0 per cent for the 2005/2006 period. These estimates indicated that there was a three percentage point drop in the proportion of the population living below the one US dollar per day poverty line between 1999/2000 and 2005/2006. This finding supports the conclusions drawn from the simple sum method results, but does not match the CATPCA method results.

The midway evaluation of the Millennium Development Goals for Tanzania (20002008) showed a decline of approximately 1.4 percentage points in the proportion of the population living below one US dollar per day between 2003/2004 and 2006/2007 (Poverty Eradication and Economic Empowerment Division, United Republic of Tanzania, 2008). These results support the findings in this study of a fall in the per cent of poor/vulnerable households in Tanzania between 2004 and 2007 by both the CATPCA and simple sum methods. Similarly, the 2009 Poverty and Human Development Report for Tanzania indicated that there was a fall in the proportion of households living on less than one US dollar per day between 2001 and 2007 (Research and Analysis Working Group, United Republic of Tanzania, 2009). Table 5 compares the direction of changes in the per cent of the population allocated to the cluster of lowest resilience over time by the CATPCA and simple sum methods with poverty trends reported in the various country MDG documents. 
Table 5: The direction of changes in the per cent of the population allocated to the relatively most vulnerable cluster over time by the CATPCA and simple sum methods compared to trends in poverty estimates reported in various MDG documents

\begin{tabular}{|l|l|l|l|l|l|}
\hline \multirow{2}{*}{ Method } & \multicolumn{5}{|l|}{ Increase/decrease in the proportion of vulnerable/poor households over time } \\
\cline { 2 - 6 } & Egypt & Kenya & Mali & Uganda & Tanzania \\
\hline CATPCA & $\uparrow$ & $\downarrow$ & $\uparrow$ & $\uparrow$ & $\downarrow$ \\
\hline Simple sum & $\downarrow$ & $\downarrow$ & $\uparrow$ & $\downarrow$ & $\downarrow$ \\
\hline MDG Report & $\downarrow$ & n/a & n/a & $\downarrow$ & $\downarrow$ \\
\hline
\end{tabular}

Note: CATPCA refers to Categorical Principal Component Analysis.

Source: Survey data (various years).

The increase/decrease for the CATPCA and simple sum methods are based on the authors' calculations using the estimated household resilience scores and reflect increases or decreases in the per cent of households allocated to the relatively poorest cluster for each country over time. The increase/decrease for the MDG Report row was taken from the country MDG reports where available from www.undp.org/mdg/reports.shtml.

It was found that the two methods of generating the resilience scores - the CATPCA and simple sum methods - did not consistently produce the same results and, therefore, the conclusions regarding the changes in the proportion of the poor and the level of resilience over time did not always concur. For Egypt, the results of the CATPCA and simple sum methods differed and support could be found in the literature for the conclusions drawn from the simple sum results. For Kenya, both methods produced similar results, for which support could be found in poverty estimates reported by the World Bank (2008) and by Suri et al. (2009). The CATPCA and simple sum methods both showed similar changes in the proportion of the relatively most vulnerable in Mali. However, the results were in contrast to trends reported by the IMF (2008). For Uganda, the CATPCA and simple sum method results differed and support for the simple sum method results and conclusions was found in the 2010 Millennium Development Goals Report for Uganda (Ministry of Finance, Planning and Economic Development - Uganda, 2010). Lastly, the results produced by the CATPCA and simple sum methods for Tanzania were in agreement with one another regarding changes in the proportion of the relatively more vulnerable between 2004 and 2007. These results were supported by poverty estimates and trends reported by the Tanzania government in two separate documents (Poverty Eradication and Economic Empowerment Division, United 
Republic of Tanzania, 2008; Research and Analysis Working Group, United Republic of Tanzania, 2009).

From these comparisons, it is clear that neither the CATPCA method nor the simple sum method was in agreement with the published poverty estimates for the analyses and in the case of Mali, neither method was supported by the literature considered. Even within the poverty literature consulted, there were differences in estimated poverty levels. The various methods and data sources used to estimate the poverty levels considered here were considerably different. These differences affect the outcomes to such an extent that different methods of estimating poverty levels and trends can produce contrasting results. Sabry (2009) suggests that if a large proportion of the population under study is considered to live near the chosen poverty line, then the variations in poverty estimates could be exaggerated as even slight differences in methodology could have large effects on the estimated numbers of the poor.

\section{CONCLUSIONS}

This article set out to develop a measure for resilience to complete the CAADP FAFS scorecard and provide a concise tool for measuring and monitoring food security in comparative ways across countries. It presents the results of the development of a resilience score tested using Demographic and Health Survey (DHS) household data for five African countries from two different time periods per country.

This analysis has shown that both resilience indices were able to detect changes in household resilience over time in the five chosen countries and often matched published poverty rates. However, the choice of methodology - CATPCA versus simple sum - in estimating the household socio-economic status scores did affect the results, producing, at times, contrasting conclusions regarding resilience changes in a number of countries. The simple sum method results matched the published national data more closely than the CATPCA method.

Importantly, the resilience scores generated using the study approach are relative and not directly comparable across countries or over time as data constraints meant that identical variables (assets included in the survey questionnaire) were not available. As the DHS uses a standard basic questionnaire contextualised by country, the assets included in the survey differ across countries. Therefore, the score is limited in its ability to identify absolute household resilience as the same score for households in two different analyses does not necessarily represent the same level of resilience. However, the resilience index and the classification of 
households into groups by cluster analysis were able to detect changes in resilience over time and, therefore, may be useful tools in monitoring changes in household resilience. 'More broadly, the score may offer a useful and simple tool for policy and programme impact for food security and development programmes that seek to improve household resilience. The score may be a helpful impact indicator to evaluate development programmes and national policy interventions.

The resilience score has a potential to measure progress towards improved household resilience and could be useful to policy makers in analysing the impact of household risk management interventions. The score provides a simple indicator of resilience to complete the food security score and enable monitoring and evaluation of country progress towards CAADP goals. The score may offer a useful and simple tool for impact assessment to predict and evaluate policy and intervention impact at various levels of society. Future research is required to confirm whether the observed changes in household asset levels are an accurate reflection of changes in household resilience, or whether the scores vary over time due to other factors or influences.

\section{ACKNOWLEDGEMENTS}

The financial assistance of the National Research Foundation (NRF) of South Africa towards this research is hereby gratefully acknowledged. Opinions expressed and conclusions arrived at are those of the authors and are not necessarily to be attributed to the NRF. The authors also thank two anonymous referees for their useful comments on an earlier draft of the article.

\section{REFERENCES}

Alinovi, L., Mane, E. and Romano, D. 2009. Measuring household resilience to food security: Application to Palestinian households. FAO Working Paper. Available at: http://www.foodsec.org/fileadmin/user_upload/eufao-fsi4dm/docs/resilience_wp.pdf (accessed 6 November 2011).

Chambers, R. 2006. Vulnerability, coping and policy (Editorial Introduction). IDS Bulletin 37(4):33-40.

Collier, P. and Gunning, J.W. 1999. Explaining African economic performance. Journal of Economic Literature 37(1):64-111. 
Committee on World Food Security. 2011. Global strategic framework for food security and nutrition: An annotated outline. Committee on World Food Security, Rome. Available at: http://www.fao.org/fileadmin/templates/cfs/Docs1011/WG_GSF/GSF_ annotated_outline_formatted_Rev1_22_Jun_11.pdf (accessed 7 November 2011).

Costantini, P., Linting, M. and Prozio, G.C. 2010. Mining Performance Data through Nonlinear PCA with Optimal Scaling. Applied Stochastic Models in Business and Industry 26(1):85-101.

Dercon, S. 2005. Risk, poverty and vulnerability in Africa. Journal of African Economies 14(4):483-488.

Dercon, S., Hoddinott, J. and Woldehanna, T. 2005. Vulnerability and shocks in 15 Ethiopian villages, 1999-2004. BASIS Collaborative Research Support Program, University of Wisconsin-Madison.

Dercon, S. 2006. Vulnerability: A micro perspective. QEH Working Paper, 149. Oxford: Department on International Development, University of Oxford.

Dercon, S. and Christiaensen, L. 2008. Consumption risk, technology adoption and poverty traps, evidence from Ethiopia. WEF Working Paper Series, 0035. World Economy and Finance Research Programme. Birkbeck, University of London.

Elbers, C., Gunning, J.W. and Kinsey, B. 2003. Growth and risk: Methodology and micro evidence. Tinbergen Institute Discussion Paper, 2003-068/2, Amsterdam: Tinbergen Institute. Available at: http://129.3.20.41/eps/dev/papers/0408/0408014.pdf (accessed 28 June 2010).

Filmer, D. and Pritchett, L.H. 1994. Estimating wealth effects without expenditure data - or tears: With an application to educational enrolments in States of India. World Bank, Policy Research Working Paper, Washington D.C.

Filmer, D. and Pritchett, L.H. 1999. The effect of household wealth on educational attainment: Evidence from 35 Countries. Population and Development Review 25(1):85120.

Filmer, D. and Pritchett, L.H. 2001. Estimating wealth effects without expenditure eata - or tears: An application to educational enrollments in States of India. Demography 38(1):115-132.

Garenne, M. and Hohmann-Garenne, S. 2003. A wealth index to screen high-risk families: Application to Morocco. Journal of Health, Population and Nutrition 21(3):235-242. 
Garson, G.D. 2010. Cluster analysis. Statnotes: Topics in multivariate analysis. North Carolina State University. Available at: http://faculty.chass.ncsu/garson/pa765/statnote.htm (accessed 27 October 2010).

Gifi, A. 1990. Nonlinear multivariate analysis. Chichester: Wiley.

Gwatkin, D.R., Rutstein, S., Johnson, K., Suliman, E., Wagstaff, A. and Amouzou, A. 2007. Socio-economic differences in heath, nutrition and population within developing countries: An overview. Country Reports on HNP (Health Nutrition and Population) and Poverty, World Bank, Washington D.C.

Hatloy, A. Hallund, J., Diarra, M.M. and Oshaug, A. 2000. Food variety, socio-economic status and nutritional status in urban and rural areas of Koutiala (Mali). Public Health Nutrition 3(1):57-65.

Hendriks, S.L. 2005. The challenges facing empirical estimation of food (in)security in South Africa. Development Southern Africa 22(1):103-123.

Hendriks, S., Kiamba, J. and Ngidi, M. 2009. Country responses to high food prices: Challenges and opportunities for Africa. Paper prepared for the April 2009 Agriculture, Livestock and Lands African Ministers' Conference and the June/July 2009 AU Heads of State Government Summit (Addis Ababa).

Hendriks, S.L. 2011. Overview: Trade for nutrition. Plenary technical paper presented at the first commemoration of the Africa Food Security and Nutrition Day, MidRand, 27-28 October, 2011.

High Level Task Force on the Global Food Crisis. 2010. Updated comprehensive framework for action. Available at: http://un-foodsecurity.org/sites/default/files/UCFA_English.pdf (accessed 7 November 2011).

IMF (International Monetary Fund). 2008. Mali: Poverty reduction strategy paper. IMF Country Report 08/121. Washington D.C: International Monetary Fund.

Kinsey, B., Burger, K. and Gunning, J.W. 1998. Coping with drought in Zimbabwe: Survey evidence on responses of rural households to risk. World Development 26(1):89-110.

Kolenikov, S. and Angeles, G. 2009. Socioeconomic status measurement with discrete proxy variables: Is principal component analysis a reliable answer? Review of Income and Wealth $55(1): 128-165$.

Linting, M. 2007. Nonparametric inference in nonlinear principal components analysis: Exploration and beyond. Dissertation (The Netherlands: Leiden University). Available at: www.openaccess.leidenuniv .nl.dspace/handle/1887/1238 (accessed 16 February 2010). 
Linting, M., Meulman, J.J., Groenen, P.J.F. and Van der Kooij, A.J. 2007. Nonlinear principal components analysis: Introduction and application. Psychological Methods 12(3):336-358.

Lovendal, C.R. and Knowles, M. 2005. Tomorrow's hunger: A framework for analyzing vulnerability to food insecurity. ESA Working Paper, 05-07, Rome: Food and Agriculture Organization of the United Nations.

Macro International Inc. 2010. Demographic and Health Survey Data (various countries and years). Available at: www.measuredhs.com (accessed 5 July 2010).

Mair, P. and De Leeuw, J. 2010. A general framework for multivariate analysis with optimal scaling: The R package aspect. Journal of Statistical Software 32(9):1-23.

Manisera, M., Dusseldorp, E. and Van der Kooij, A.J. 2010. Identifying the component structure of satisfaction scales by nonlinear principal components analysis. Quality Technology and Quantitative Management 7(2):97-115.

Manly, B.F.J. 1994. Multivariate statistical methods: A primer (Second edition). London: Chapman and Hall.

Maxwell, S. and Smith, M. 1992. Household food security: A conceptual review. In M. Maxwell and T.R. Frankenberger (eds.), Household food security: Concepts, indicators and measurements. A technical review, 1-7. New York and Rome: UNICEF/ IFAD.

McKenzie, D.J. 2005. Measuring inequality with asset indicators. Journal of Population Economics 18:229-260.

Measure DHS. (undated). DHS method questionnaires. Measure DHS: ICF International, Calverton. Available at: www.measuredhs.com/What-We-Do/Survey-Types/DHSQuestionnaires.cfm (accessed 8 November 2013).

Meulman, J.J., Heiser, W.J. and SPSS Inc. 2004a. SPSS Categories 13.0. Chicago: SPSS Inc.

Meulman, J.J., Van der Kooij, A.J. and Heiser, W.J. 2004b. Principal components analysis with nonlinear optimal scaling transformations for ordinal and nominal data. In D. Kaplan (ed.), The sage handbook of quantitative methodology for the social sciences. California: Sage Publications Inc.

Ministry of Economic Development - Egypt. 2010. Egypt's progress towards achieving the millennium development goals 2010 (Cairo: Ministry of Economic Development - Egypt and the United Nations Development Programme). Available at: www.undp.org/mdg/reports. shtml (accessed 17 February 2011).

Ministry of Finance, Planning and Economic Development - Uganda. 2010. Millennium development goals report for Uganda, 2010 (Kampala: Ministry of Finance, Planning and 
Economic Development). Available at www.undp.org/mdg/reports.shtml (accessed 17 February 2011).

Montgomery, M.R., Gragnolati, M., Burke, K. and Paredes, E. 1999. Measuring living standards with proxy variables. Demography 37(2):155-174.

Moser, C. and Holland, J. 1997. Household response to poverty and vulnerability. Volume 4: Confronting Crisis in Carvana, Lusaka, Zambia. Urban Management Programme Report, 24. Washington D.C: World Bank.

Moser, C. 1998. The asset vulnerability framework: Reassessing urban poverty reduction strategies. World Development 26(1):1-19.

NEPAD (The New Partnership for Africa's Development). 2009. Comprehensive African Agriculture Development Programme (CAADP) Pillar 3, Framework for African Food Security (FAFS). Midrand: NEPAD.

Norusis, M.J. 2008. SPSS 16.0 Statistical procedures companion. New Jersey: Prentice Hall Inc.

Poverty Eradication and Economic Empowerment Division, United Republic of Tanzania. 2008. Millennium Development Goals Report: Mid-way Evaluation, 2000-2008, Ministry of Finance and Economic Affairs, Dar-es-Salaam.

Research and Analysis Working Group, United Republic of Tanzania. 2009. Poverty and Human Development Report 2009, Ministry of Finance and Economic Affairs, Dar-esSalaam.

Rosenzweig, M.R. and Binswanger, H.P. 1993. Wealth, weather risk and the composition and profitability of agricultural investments. The Economic Journal 103(416):56-78.

Rutstein, S.O. and Johnson, K. 2004. The DHS (Demographic and Health Survey) wealth index, DHS Comparative Report No. 6, OCR Macro Calverton, Maryland.

Sabry, S. 2009. Poverty lines in Greater Cairo: Underestimating and misrepresenting poverty. International Institute for Environment and Development (IIED), Working Paper 21.

Sen, A. 1981. Poverty and famines: An essay on entitlement and deprivation. Oxford: Clarendon Press.

Suri, T., Tschirley, D., Irungu, R.G. and Kariuki, D. 2009. Rural incomes, inequality and poverty dynamics in Kenya. Nairobi: Tegemeo Institute of Agricultural Policy and Development.

Swift, J. 2006. Why are rural people vulnerable to famine? IDS Bulletin 37(4):41-49. 
UNDP (United Nations Development Programme). 2008. Egypt Human Development Report 2008: Egypt's social contract: The role of civil society. Cairo: United Nations Development Programme and the Institute of National Planning.

UNDP (United Nations Development Programme). 2009. Human Development Report, 2009, Overcoming barriers: Human mobility and development. Hampshire and New York: Palgrave Macmillan.

Vyas, S. and Kumaranayake, L. 2006. Constructing socio-economic status indices: How to use principal component analysis. Health Policy and Planning 21(6):459-468.

World Bank. 2008. Kenya poverty and inequality assessment, Volume 1: Synthesis Report. Report 44190-KE, Poverty Reduction and Economic Management Unit, African Region. Washington D.C: World Bank. 